\title{
Participação dos coletivos de cultura da zona sul da cidade de São Paulo na formulação da lei de fomento à cultura da periferia
}

\author{
Graciela Rivera Guillén Medina*
}

\begin{abstract}
Resumo
O marco da redemocratização brasileira, estabelecido na concretização da Constituição Federal de 1988, abriu portas para a participação social, corroborando uma gestão pública sustentada em pilares democráticos. É pretensão deste artigo a apresentação de um movimento organizado da sociedade cujo objetivo foi a criação e implementação de uma política capaz de dar respaldo às demandas no campo da cultura na periferia da cidade de São Paulo, algo possibilitado pelo cenário da democracia participativa. Ademais, propõe-se uma discussão acerca do conceito de política pública em contraposição à ação pública.
\end{abstract}

Palavras-chaves: participação, cultura, política pública, ação pública.

\begin{abstract}
The framework of Brazilian redemocratization established in the implementation of the Federal Constitution of 1988 opened doors for social participation, corroborating public management based on democratic pillars. This article aims to present an organized movement of society whose objective was the creation and implementation of a policy capable of supporting the demands in the field of culture in the periphery of the city of São Paulo, which was possible by the scenario of participatory democracy. In addition, it is proposed a discussion about the concept of public policy as opposed to public action.
\end{abstract}

Keywords: participation, culture, public policy, public action.

\footnotetext{
*Bacharelanda em Ciências e Humanidades na UFABC - contato: graciela.medina@aluno.ufabc.edu.br
} 


\section{Introdução}

Em julho de 2016, último ano da gestão Haddad na prefeitura municipal de São Paulo, foi promulgada a Lei 16.496. A Lei em questão foi responsável por instituir o Programa de Fomento à Cultura da Periferia de São Paulo, cuja finalidade é principalmente "apoiar financeiramente projetos e ações culturais propostos por coletivos artísticos e culturais em distritos ou bolsões com altos índices de vulnerabilidade social, especialmente nas áreas periféricas do Município" (Art. $1^{\circ}$ da Lei).

O Programa instituído pela Lei prevê editais anuais que têm por finalidade a seleção de projetos e ações culturais surgidos na periferia para serem contemplados por um recurso financeiro, o qual pode ser de 100 a 300 mil reais.

É inegável o fato de que a Lei representa para os trabalhadores da cultura bem como para todos os moradores da periferia de São Paulo uma conquista de caráter essencialmente popular. Considerando a participação fundamental da sociedade civil neste processo, esta reflexão pretende, como apontado pelo título que leva, descrever de maneira sucinta a luta dos coletivos de cultura, aqui representados pelo Movimento Cultural das Periferias. No entanto, o foco será a articulação das mobilizações das quais a zona sul da cidade participou ou ainda protagonizou.

Para além de uma simples descrição dos desdobramentos das ações levadas a cabo pelo Movimento e sua articulação com o governo local, é também interesse deste estudo a observação das políticas públicas para além de sua conceitualização como serviços oferecidos pelo governo, entendendo a existência de uma via de mão dupla e não simplesmente a ação unilateral do Estado. Para isso, será utilizada a ideia de "ação pública" e a sua relação com a noção de "fadiga" do conceito "política pública" (SPINK, 2015). As ideias de participação e poder local serão priorizadas e o caso da Lei de Fomento representa um contexto perfeito para sustentar esta discussão.

Por meio do estudo de um caso prático, a proposta é também colaborar para a produção já iniciada sobre os diferentes significados de um único conceito: política pública. Ademais, entende-se que o conhecimento e, principalmente, o registro das dinâmicas que foram utilizadas pelo Movimento em sua articulação interna e institucional são fundamentais para inspirar e orientar outras lutas.

\section{A luta do movimento cultural das periferias pela lei ${ }^{1}$}

As ações e os eventos de expressão cultural existem já há muito na periferia da zona sul. No entanto, houve um marco na região que representou o início da articulação da cultura com outras pautas da cidade e, posteriormente, com outras regiões, o que motivou e viabilizou a luta das periferias pela Lei de Fomento.

Inspirado pelo Sarau do Binho e pela Cooperifa, o Sarau da Vila do Fundão (no qual aconteciam apresentações culturais nas diferentes linguagens culturais e artísticas), foi fundado em novembro de 2009 por Fernando Ferrari ${ }^{2}$ e outros traba-

1 Toda a informação contida nesta seção é fruto de uma roda de conversa realizada em novembro de 2017 durante o "VII Fórum Social Sul: uma outra periferia é possível, necessária e urgente", realizado na Paróquia Santos Mártires (Jd. Ângela, São Paulo). Na ocasião, Fernando Ferrari compartilhou com as pessoas presentes parte de sua atuação no Movimento de Cultura e falou bastante sobre as articulações necessárias para que a Lei de Fomento se concretizasse

2 Trabalhador da cultura e atualmente "co Deputado Estadual" (mandato coletivo da deputada Mônica 
lhadores da cultura da região, buscando resgatar as lutas do território, articulando-se com as demandas locais e impulsionar outras mobilizações na periferia na luta pela habitação e também por direitos à cidade em relação à infraestrutura da periferia, organizando-se para solicitar a colocação de semáforos, manutenção de córregos e etc.

Neste contexto de atuação nas questões sociais enfrentadas pela comunidade no nível local, o pessoal do Sarau da Vila do Fundão, entendendo que os problemas ali enfrentados acometiam também outras zonas do município, buscou articular-se com as demais regiões. Assim, o pessoal da Vila do Fundão aproximou-se mais da zona noroeste (Osasco, principalmente) e começou a participar também do Mutirão Cultural das Quebradas, que promovia em espaços públicos shows de música, dança, teatro e poesia. Muitas vezes, a estratégia utilizada era fechar uma rua para que as ações pudessem ocorrer num local acessível para todos. A participação do governo foi nula no Mutirão Cultural. O ato de ocupar os espaços públicos para realizar o Mutirão, inclusive, buscava retratar a denúncia vinda da sociedade civil organizada do abandono ou da presença insuficiente do poder público em relação à cultura na periferia.

Além disso, há um nó de extrema relevância nesta rede que conectava as diferentes "quebradas" (expressão que pode ser utilizada de maneira preconceituosa, definindo as periferias como lugares necessariamente inseguros e violentos; de forma neutra ou ainda carinhosa, utilizada para referir-se com respeito a um bairro da periferia) espalhadas pela cidade foi a articulação com a zona leste. Foi no Fórum de Cultura da Zona Leste em que vários fóruns periféricos se encontraram para discutir questões comuns a todos os trabalhadores da cultura na periferia. Houve o estudo de uma tese acadêmica sobre o sujeito periférico (D'ANDREA, 2013) (o que indica, ainda que em menor intensidade, uma participação da universidade no processo) e o consenso de que as pautas de cada região eram na verdade pautas de todas as periferias da cidade, que conformavam uma só luta. Inclusive com a presença da Rede Popular de Cultura M’Boi e Campo Limpo, se iniciou o "tecimento" do que Fernando Ferrari, trabalhador da cultura e liderança no movimento cultural nomeou de "arco da periferia" e, como desdobramento inicial do processo de articulação das diferentes regiões, iniciou-se a escrita da Lei de Fomento.

Para isso foram criados grupos de trabalho em cada quebrada. Os trabalhadores e coletivos estudaram exaustivamente a legislação já existente para produzir o texto da Lei de Fomento à Cultura da Periferia - o que significa que a lei é de cunho popular. Além disso, o que deu ainda mais força para o Movimento Cultural foi o fato de a periferia ter tido uma forte presença na III Conferência Municipal de Cultura (realizada em 2013), o que colocou a demanda pela Lei como a segunda pauta mais importante no balanço da Conferência.

Após essa conquista de visibilidade que então a luta pela Lei foi além. O Movimento, que já pressionava anteriormente tanto o governo municipal quanto federal ${ }^{3}$,

Seixas, junto a Anne Rammi, Chirley Pankará, Erika Hilton, Paula Aparecida, Jesus dos Santos, Claudia Visoni, Raquel Marques e Fernando Ferrari) pertencente à Bancada Ativista (página da Bancada no facebook: https://www.facebook.com/bancadaativista/)

3 A principal estratégia era a produção e entrega de cartas de denúncia aos governantes, em nome de todos os trabalhadores e coletivos da periferia. Isso trouxe muitos avanços para a questão das Casas de Cultura, por exemplo, já que o então prefeito de São Paulo, Fernando Haddad, transferiu a responsabilidade da gestão das Casas das subprefeituras para a Secretaria Municipal de Cultura. 
passou a articular na Câmara Municipal de São Paulo, demonstrando a diversos vereadores a importância da Lei e reivindicando direitos. Neste processo, além das várias conversas, houve também a ocupação da Câmara. O Movimento resistia diante das dificuldades e dos obstáculos que apareciam na luta.

Foi a partir deste momento que o grupo que participou presencialmente das reuniões na Câmara e na Secretaria Municipal de Cultura representou o Movimento Cultural das Periferias. Foram defendidos os principais pontos da lei apresentando os efeitos da reparação histórica, considerando o fato de que a população periférica vive em uma constante exposição às vulnerabilidades do território. Além disso, foi posto que suas potencialidades são reprimidas devido à ausência de uma distribuição justa do orçamento da cidade (neste caso dos recursos destinados à cultura), que há anos se concentra na região central. Frente à essa realidade, o Movimento exigia que a destinação dos recursos fosse baseada na renda per capita (até meio salário mínimo), além de considerar a área de residência. Outra questão de extrema importância era a priorização do repasse para pessoa física, tendo em conta a dinâmica do Programa, que deveria contemplar moradores e coletivos que trabalhassem com projetos e ações culturais - e não empresas (ainda que tivessem finalidades similares ou até mesmo iguais). Além disso, por questões burocráticas, a obrigatoriedade do CNPJ (Cadastro Nacional de Pessoa Jurídica) representava, na verdade, mais um obstáculo no acesso ao fomento.

Para o primeiro edital, foram reivindicados 20 milhões de reais e, após a aprovação da Lei, foram disponibilizados apenas 7 milhões de reais. Apesar de não ter conseguido o valor desejado para o Programa de Fomento, o Movimento, após muita pressão sobre o poder público, conseguiu participar do remanejamento do orçamento da cultura, transferindo do Teatro Municipal para o Transporte Escolar Gratuito - TEG o valor de 12 milhões de reais, o que indica a efetividade da articulação com outras lutas.

A aprovação da Lei 16.496 significou uma conquista enorme para o Movimento Cultural das Periferia, porém é importante destacar que o processo não se resumiu a debates e negociações. Os grupos que compunham (e ainda compõem) o Movimento enfrentaram diversas dificuldades no árduo caminho para a aprovação da Lei, incluindo a insatisfação de algumas necessidades básicas, como a alimentação e, também, o direito de mobilidade na cidade. O resultado da desvalorização do trabalhador da cultura é intensificado quando não havia recurso para o deslocamento dos bairros periféricos até o centro da cidade - onde estão situadas a Câmara Municipal de Vereadores e a Secretaria da Cultura. Segundo Fernando Ferrari, "a Lei foi escrita sangrando".

\section{O diálogo com o governo municipal}

Para mostrar neste trabalho a perspectiva do poder público em relação a como foi o processo de formulação e aprovação da Lei de Fomento às Periferias, foi realizada uma entrevista com uma profissional do setor público que possui experiência de mais de 30 anos na prefeitura. Além disso, a pessoa entrevistada esteve muito presente precisamente nos diálogos com o Movimento Cultural enquanto faziam suas reivindicações em relação à Lei de Fomento à Cultura da Periferia.

Sua carreira teve início na Secretaria da Habitação, como estagiária durante a 
graduação. Desde então, passou por uma Casa de Cultura, pela Câmara Municipal de Vereadores e, também, pela Secretaria Municipal da Cultura. Na Câmara, trabalhou com o vereador Nabil, que fez parte da criação do programa VAI - Valorização de Iniciativas Culturais, o qual subsidia projetos artístico-culturais produzidos por jovens de baixa renda. Assim que terminou o mandato de Nabil, a profissional voltou para a Secretaria de Cultura e trabalhou no VAI por quatro anos. Esta experiência fez com ela pudesse ter ainda mais contato com os movimentos de cultura e, principalmente, com a juventude moradora da periferia.

Ela conta que já no processo de gestação, o VAI recebeu muitas críticas de bancos que questionavam os valores altos de repasse (no início do programa, o recurso destinado a cada projeto era de 15 mil reais) para jovens que nunca haviam tido uma conta bancária - e isso dificultava a abertura das contas, por exemplo. Dessa maneira, a profissional entrevistada afirma que a implementação do VAI foi um verdadeiro desafio para a prefeitura.

Depois de um tempo de existência do VAI, começaram a surgir alguns questionamentos do pessoal já contemplado, uma vez que já não eram mais jovens, não poderiam receber recursos do programa para dar continuidade aos seus projetos. Diante disso, mesmo com a criação de uma outra modalidade do programa, o VAI II, a demanda por valores maiores existia e passava a conformar uma importante pauta dos trabalhadores da cultura, o que motivou a luta pela Lei de Fomento.

A partir da Lei de Fomento ao Teatro (programa pioneiro na questão do fomento e aprovado em 2001), vários segmentos da cultura começaram a se mobilizar, como o da Dança - que resultou na Lei de Fomento à Dança. Inspirando-se nessas duas leis, bem como no VAI, que apoiava quaisquer ações culturais na periferia, isto é, não vinculadas a alguma linguagem específica, o pessoal da música, do circo e da cultura periférica começaram também a sua luta.

Além de lutar pela continuação do VAI, a periferia já se organizava entre os vários coletivos culturais para pautar uma Lei de Fomento destinado exclusivamente à população periférica ou exposta a vulnerabilidades. Além disso, a internet expandiu o alcance da comunicação e a própria modalidade II do programa VAI apoiava os projetos promotores da articulação em rede, o que pode ter fortalecido essa conexão.

Com o intuito de conquistar um programa que, diferentemente do VAI, garantisse a continuidade dos projetos e ações, houve o estabelecimento da Lei de Fomento à Cultura da Periferia como uma das principais demandas na III Conferência Municipal de Culturas.

Na época, a prefeitura não tinha clareza em que a Lei se diferenciaria do VAI na hora de selecionar os projetos contemplados. Neste sentido, o Movimento passou a se reunir para pesquisar a legislação existente e fazer sua proposta. Segundo a entrevistada em 2017, "eles pegaram o melhor de cada edital. O que consideravam legal em cada programa e edital que existia, pegaram e colocaram no texto-base da Lei de Fomento".

Entre os pontos prioritários que o Movimento considerava mais favoráveis, estavam a multiplicidade de ações, o apoio à pessoa física e o modelo de prestação de contas do VAI, como o formato de eleição, de seleção e dos valores de repasse do fomento. Em 2015, após percorrer toda a cidade para debater essa ideia com todas as regiões, o grupo que se apresentava à frente da luta, agendou uma reunião com a 
Secretaria Municipal da Cultura para finalmente apresentar o texto base da proposta de lei.

Criou-se, então, um Grupo de Trabalho na prefeitura, o qual, segundo a profissional entrevistada, tinha o objetivo de tornar a proposta exequível. No sentido de viabilizar a aprovação da lei, o poder público foi sugerindo ajustes para que as chances de passar pelo legislativo fossem maiores. Nesse momento apareceram algumas tensões, visto que havia muitas questões bastante delicadas e, principalmente, importantes para o Movimento e tiveram que ser exaustivamente debatidas.

Uma dessas questões era o subsídio para a pessoa física. O poder público questionava essa pauta com base nos altos valores repassados numa política de fomento. No programa VAI, como os valores são baixos é possível realizar a prestação de contas através de recibos simples. No fomento, isso já não seria possível, o que representava um ponto de discórdia entre o Movimento e o governo.

Para solucionar essa questão, decidiu-se que o repasse aconteceria na forma de bolsa, nos moldes da Fapesp. No entanto, essa bolsa consideraria diferentes níveis de participação nos projetos e ações, o que levaria a uma categorização dos trabalhadores e, por essa razão, feria o princípio de não hierarquização, um dos mais importantes do Movimento. Assim, para manter o repasse para pessoa física, o Movimento Cultural das Periferias aceitou uma prestação de contas mais rigorosa. Havia também uma outra questão: alguns dos critérios obrigatórios para participar do programa propostos pelo Movimento eram muito difíceis de averiguar e checar a sua veracidade, como por exemplo, a obrigatoriedade de residência de pelo menos três anos na área na qual o proponente afirmasse viver.

Considerando o grande número de residências para comprovar e as diferentes estruturas domiciliares que existem nas regiões periféricas, sendo este um requisito difícil de checar, por essa razão, apesar da intenção de garantir que a maior parte dos recursos sejam de fato destinados à periferia, não evita efetivamente que alguns proponentes ajam de "má fé" para acessar os recursos. Essa questão, apesar de ter sido aprovada e constar na Lei, segundo a entrevistada, não foi suficientemente discutida e estabelecer critérios difíceis de acompanhar pode desmoralizar a Lei.

Para o poder público, o processo de aprovação da Lei significou um momento de aproximação da relação governo e sociedade civil organizada. Sobre a zona sul especificamente, a profissional entrevistada comenta que se trata de uma região que desde o começo do VAI destacou-se em relação ao volume de projetos propostos e aprovados. A zona sul já foi considerada extremamente violenta e até hoje muitos dos bairros lá localizados estão expostos a diversas vulnerabilidades. No entanto, ao mesmo tempo se apresenta um boom cultural, mostrando, para além de suas vulnerabilidades, as suas potencialidades.

\section{Política pública e ação pública}

Quando se discute o que é política pública, é preciso observar que não existe uma única verdade acompanhada de um único significado. As noções mais difundidas são normalmente as de Mead (1995), Lynn (1980), Peters (1986) e Dye (1984), todas resumidas exclusivamente ao fazer governamental e, também, a de Laswell, que apresenta a noção de políticas públicas mais como um campo, quase na perspectiva bourdiana (SOUZA, 2006). 


\begin{abstract}
Mead (1995) a define como um campo dentro do estudo da política que analisa o governo à luz de grandes questões públicas e Lynn (1980), como um conjunto de ações do governo que irão produzir efeitos específicos. Peters (1986) segue o mesmo veio: política pública é a soma das atividades dos governos, que agem diretamente ou através de delegação, e que influenciam a vida dos cidadãos. Dye (1984) sintetiza a definição de política pública como "o que o governo escolhe fazer ou não fazer". A definição mais conhecida continua sendo a de Laswell, ou seja, decisões e análises sobre política pública implicam responder às seguintes questões: quem ganha o quê, por quê e que diferença faz. (SOUZA, p. 24, 2006)
\end{abstract}

No geral, o termo, que tem sido cada vez mais utilizado nos diferentes âmbitos e não somente no campo de públicas, tornou-se sinônimo de qualquer agir governamental (SPINK, 2015). Entendendo que a "política pública" não é a única linguagem do fazer público possível, mas sendo parte de um grupo de linguagens, Spink (2015) propõe a reflexão sobre a "ação pública", que vai além da ação governamental direcionada à população e que abarca as ações da própria população para a população, que muitas vezes enfrenta seu governo.

Neste sentido, poderíamos considerar a promulgação da Lei de Fomento à Cultura da Periferia como uma política pública dentro dos moldes apresentados por Souza (2009), pois o poder público foi o responsável pela concretização atendendo a uma demanda da população. Não obstante, se analisada a trajetória percorrida pelos diferentes atores envolvidos no processo de criação, de luta ${ }^{4}$ e de implementação da Lei, não se trata de uma ação pública? A população beneficiária da ação, que foi além do estabelecimento e vocalização de uma demanda, reivindicou a participação ativa em todo o processo de discussão para a criação e efetivação deste pleito. Além disso, estudou os meios para dar viabilidade e debateu com o poder público para que a Lei fosse promulgada dentro do que fosse favorável para a população - num exercício árduo de negociação e, também, de resistência. Não seria o Movimento de Cultura tão responsável quanto (ou até mais) o próprio governo municipal?

Experiências como esta põe fim à ideia da satisfação das demandas populares como um movimento que vem de cima para baixo. A sociedade deixa de desempenhar um papel passivo para construir, junto ao poder público, um contexto em que todos os atores são ativos. Segundo Spink (2015), a ideia central da ação pública é que "governos não têm o monopólio sobre o público e que o público nunca abriu mão da sua disposição de agir publicamente".

Ademais, é importante esclarecer que a ação pública nem sempre envolve a colaboração com o governo. Uma ação pública pode estar constituída de forma exclusiva por atores da sociedade civil, como mostrado pela experiência catalã, entre outras, de serviços comunitários sem absolutamente nenhum envolvimento do poder público.

Pensar la gestión comunitaria como puesta en jaque de la dicotomía Mercado-Estado es políticamente útil, un giro interesante

4 A luta em si, conceito tão utilizado nos movimentos sociais, pode ser pensada como a necessidade que muitos populações encontram de enfrentar seus governos, como explanado por Spink (2015). O "enfrentamento" está dirigido à questão da tensão na reivindicação: muitos grupos têm dificuldade em vocalizar as suas demandas, isto é, a participação, por mais que em uma democracia estejam estabelecidos os meios institucionais para efetivá-la, nem sempre é simples e fácil. 
para superar esa doble vía que tanto ha marcado las formas de gobierno de lo que nos es común. El mensaje es claro: hay vida fuera de los muros de lo público-estatal y lo privado-mercantil. (OBSERVATORIO METROPOLITANO DE BARCELONA, 2014)

É preciso cautela para não confundir a expansão da ação pública com a admissibilidade do abandono do Estado em relação ao seu papel como garantidor de direitos. Neste sentido, Dagnino (2014) ilustra com maestria os efeitos da confluência perversa, produto de dois projetos distintos acontecendo concomitantemente no Brasil: o marco da redemocratização com a promulgação da Constituição Federal de 1988 (CF/88) que estabeleceu fortes preceitos de participação; entretanto com o fortalecimento do neoliberalismo com a eleição de Fernando Collor, acabaram sendo empurradas para a população as responsabilidades do governo.

\section{Considerações Finais}

Sobre a relação dos coletivos com o poder público na etapa de aprovação da lei, a Secretaria se posiciona realmente como ator que ao contrário de impor obstáculos a esse processo, tinha a intenção de tornar a proposta da lei factível para que a mesma tivesse chances de ser aprovada na Câmara e promulgada pelo prefeito. Portanto, a Secretaria de Cultura concorda que a Lei 16.496 é resultado de iniciativa, mobilização, estudo e luta do Movimento Cultural das Periferias, mas coloca-se como ator fundamental no processo em questão.

Além disso, a Secretaria aponta que apesar da vitória representada pela aprovação, a Lei ainda apresenta pontos que não puderam ser suficientemente discutidos (até mesmo pela questão de pressa em aprová-la). Por isso, seria interessante empenhar mais esforços para promover o amadurecimento dessas questões, o que pode significar outra luta, visto que a atual gestão não se mostra muito aberta ao debate com os coletivos, pois prioriza a "programação para o cidadão" e não para "grupos específicos"; assim, prioriza aspectos individuais em detrimento dos coletivos.

Por fim, observa-se que a participação não se trata de um afetuoso convite do poder público à população para que esta participe ativamente da gestão pública levando adiante propostas que serão efetivamente discutidas e avaliadas quanto à sua viabilidade. Para aqueles que desejam participar, há uma verdadeira luta a enfrentar, pois na conjuntura atual brasileira, verifica-se que os pressupostos da $\mathrm{CF} / 88$ relacionados à participação (e todo o resto) não são conquistas permanentes sem possibilidade de revoga. Tudo indica que a luta pela participação será cada vez mais dura e a persistência deverá ser cada vez maior.

\section{Referências bibliográficas}

Blog Fórum de Cultura da Zona Leste. Lei de Fomento à Periferia: Histórico e Apresentação. 2015. Disponível em: <http://forumdeculturadazonaleste.blogspot.com/2015/ 07/lei-de-fomento-periferia-historico-e.html?q=lei+de+fomento $>$. Acesso em: $21 \mathrm{de}$ Março de 2019.

CÂMARA MUNICIPAL DE SÃO PAULO (Município). Lei no 16.496, de 20 de julho de 2016. Instituição do Programa de Fomento à Cultura da Periferia de São Paulo. São 
Paulo, SP, 2016. Disponível em: <http://documentacao.camara.sp.gov.br/iah/fulltext/ leis/L16496.pdf>. Acesso em: 24 mar. 2019.

DAGNINO, E. Construção democrática, neoliberalismo e participação: os dilemas da confluência perversa. Política Sociedade, Florianópolis, v. 3, n. 5, p.139-164, 2004. Disponível em: <https://periodicos.ufsc.br/index.php/politica/article/view/1983/1732>. Acesso em: 24 de Março de 2019.

D'ANDREA, T. P. A Formação dos Sujeitos Periféricos: Cultura e Política na Periferia de São Paulo. Tese de Doutorado. Universidade de São Paulo, Programa de Pós-Graduação em Sociologia, 2013.

OBSERVATORIO METROPOLITANO DE BARCELONA. Comunes Urbanos en Barcelona. Barcelona, 2014. Disponível em: <http://bcncomuns.net/wp-content/uploads/2014/ 06/Conclusions_OMB_ESP.pdf>. Acesso em: 21 de Março de 2019.

SOUZA C. Políticas públicas: uma revisão da literatura. Sociologias, Porto Alegre, v. 8, n. 16, p. 20-45, jul/dez. 2006. Disponível em: <http://www.scielo.br/pdf/soc/n16/ a03n16>. Acesso em: 20 de Abril de 2019.

SPINK, P. Pesquisa de campo em psicologia social: uma perspectiva pós-construcionista. Psicologia Sociedade, São Paulo, v. 15, n. 2, p. 18-42, 2002. Disponível em: <http://www. scielo.br/scielo.php?pid=s0102-71822003000200003\&script=sci_abstract\&tlng=pt $>$. Acesso em: 21 de Março de 2019.

SPINK, P. Para Além da Política Pública: política pública e as múltiplas linguagens da ação pública. In: Anais do I ENEPCP, I Encontro Nacional de Ensino e Pesquisa do Campo de Públicas, Brasília, dez. 2015. Disponível em: <https://www.researchgate.net/ publication/293811328_Para_Alem_da_Politica_Publica_politica_publica_e_as_multiplas_ linguagens_da_acao_publica>. Acesso em: 21 de Março de 2019. 